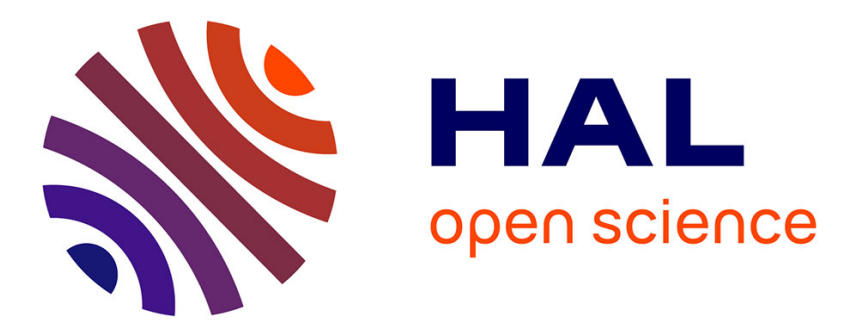

\title{
Blackout of my nights: Contentless, timeless and selfless report from the night in patients with central hypersomnias
}

\author{
Emma Chabani, Marie Charlotte Vionnet, Romy Beauté, Smaranda \\ Leu-Semenescu, Pauline Dodet, Isabelle Arnulf
}

\section{To cite this version:}

Emma Chabani, Marie Charlotte Vionnet, Romy Beauté, Smaranda Leu-Semenescu, Pauline Dodet, et al.. Blackout of my nights: Contentless, timeless and selfless report from the night in patients with central hypersomnias. Consciousness and Cognition, 2020, 81, pp.102931. 10.1016/j.concog.2020.102931 . hal-02880847

\section{HAL Id: hal-02880847 \\ https://hal.sorbonne-universite.fr/hal-02880847}

Submitted on 25 Jun 2020

HAL is a multi-disciplinary open access archive for the deposit and dissemination of scientific research documents, whether they are published or not. The documents may come from teaching and research institutions in France or abroad, or from public or private research centers.
L'archive ouverte pluridisciplinaire HAL, est destinée au dépôt et à la diffusion de documents scientifiques de niveau recherche, publiés ou non, émanant des établissements d'enseignement et de recherche français ou étrangers, des laboratoires publics ou privés. 
E. Chabani, et al.

Blackouts of my nights: contentless, timeless and selfless report from the night in patients with central hypersomnias

Emma Chabani ${ }^{a, b}$, Marie Charlotte Vionnet ${ }^{a}$, Romy Beauté ${ }^{a}$, Smaranda Leu-Semenescu ${ }^{b, c, d}$, Pauline Dodet ${ }^{b, c, d}$, Isabelle Arnulf $f^{a, b, c, d^{*}}$

${ }^{a}$ Sorbonne University, Paris, France

${ }^{\mathrm{b}}$ Brain Research Institute (CRICM - UPMC-Paris6; Inserm UMR_S 975; CNRS UMR 7225) Paris, France

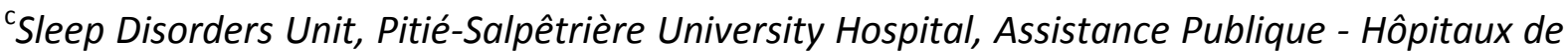
Paris, Paris, France

${ }^{\mathrm{d}}$ National Reference Center on Narcolepsy and Rare Hypersomnias, France.

*Corresponding author address: Service des pathologies du sommeil, Hôpital PitiéSalpêtrière, 47-83 boulevard de l'Hôpital, 75013 Paris, France.

E-mail address: isabelle.arnulf@aphp.fr

Conflict of interest: the authors have no conflict of interest relative to this study. 
E. Chabani, et al.

\section{Highlights}

- The report of no experience between sleep onset and offset defines night blackout

- Half of patients with idiopathic hypersomnia $(\mathrm{IH})$ had frequent night blackout

- Night blackout was less frequent in narcolepsy and rare in healthy subjects

- Slow wave sleep was higher in IH patients with than without frequent night blackout

- The subjective absence of thoughts, self-experience, and time upon awakening exists 
E. Chabani, et al.

\section{Abstract}

At the extreme spectrum of consciousness during sleep, some patients with rare hypersomnias reported experiencing a specific night 'blackout' when sleeping, i.e., an absence of experiences or recall of them from sleep onset to offset. Thus, we explored through questionnaires the conscious experiences (dreaming experience, mind, self) during the night in 133 patient with idiopathic hypersomnia, 108 patients with narcolepsy, and 128 healthy controls. The night blackout was more frequent in idiopathic hypersomnia than in narcolepsy and control groups. Patients with idiopathic hypersomnia and frequent night amnesia had lower dream recall frequencies, and felt more often sleep as deep and mind as blank during the night. They had a higher proportion of slow wave sleep on their (retrospectively collected) sleep recordings than those without night blackout. This night blackout provides a new model for studying loss of consciousness during sleep, here as a contentless, selfless and timeless feeling upon awakening.

Key words: consciousness, hypersomnia, narcolepsy, non-dreamer, self, amnesia, blackout 
E. Chabani, et al.

\section{Introduction}

What do we remember from our nights? We may recall various events, including some brief awakenings, some perceptive experiences of bodily sensations, the feeling of having dreamt without recalling the dream content, sleep mentation (non-immersive imagery and sleep thinking) and the classical dreaming experience (an immersive spatiotemporal hallucination) (Noreika, Valli, Lahtela, \& Revonsuo, 2009; F Siclari et al., 2017). The absence of all experiences mentioned above has been studied by philosophers of mind and suggested to be "pure subjective temporality" by Windt (2015). It has also been indirectly described in literature, as even non dreamers know that they have slept, and that they went through a 7 hour-long night (Pagel, 2003). Now, is there any contentless and timeless experience of the night, in the sense of awakening with the feeling that nothing (including the feeling that no time has elapsed) was experienced throughout the night, as if one was unconscious from sleep onset to sleep offset? During clinical interviews with patients suffering from a rare hypersomnia, named idiopathic hypersomnia $(\mathrm{IH})$, several patients reported to us the following experience: "I put my head on the pillow and wake up the next morning with no recall of what has happened in between and no idea that time has elapsed in-between", a report that was suggestive of contentless, selfless and timeless nights. Consequently, we decided to pay attention to this dimension that we called 'night blackout' as a possible new part of this spectrum of sleep and night perception, which resembled the 'black out' phenomenon described in acute alcoholic drinking. This term includes the idea that the subject wakes up without any feeling that time has elapsed since sleep onset. Does it corresponds to a total loss of phenomenal consciousness during night? Is the perception of 
E. Chabani, et al.

time lost during the night in subjects with night blackout? Or do they fail to encode or retrieve conscious experiences from the night? This is an open question.

Idiopathic hypersomnia is a rare, chronic and disabling disease that mostly starts in adolescents and young adults. Patients suffer from excessive daytime sleepiness despite normal or increased nighttime sleep duration, and many suffer from long (e.g., several hours) but usually unrefreshing naps (American Academy of Sleep Medicine, 2014; Arnulf, Leu-Semenescu, \& Dodet, 2019). In addition, 30 to $67 \%$ of patients report major difficulties in waking up in the morning (a symptom named 'severe morning inertia' or 'sleep drunkenness'), impaired daytime alertness (the feeling of never being really awake, of being foggy), and automatic behaviors (loss of conscious awareness for their actions, leading to errors such as writing gibberish or interrupting a conversation with a completely different topic), all symptoms suggestive of states intermediary to sleep and wake (Vernet, LeuSemenescu, Buzare, \& Arnulf, 2010). The cause of IH is yet unknown, as the hypocretin (deficient in narcolepsy type 1 , another rare central hypersomnia) and histamine arousal systems are intact in $\mathrm{IH}$.

Here, we first based our research on clinical interviews, interviewing patients with $\mathrm{IH}$ during their routine, yearly visits and catching the exact words they used to describe this night blackout. We then decided to better circumscribe this concept of night blackout by systematically examining (via a questionnaire) all kinds of mentation when falling asleep, going through the night and upon awakening, including the frequency and quality of dreaming and thinking. We further looked at demographical, clinical and sleep (using retrospective polysomnography measures) determinants of the night blackout phenotype. Later, we wanted to determine whether this night blackout was specific to $\mathrm{IH}$, and applied 
E. Chabani, et al.

the questionnaires to narcolepsy patients (as an example of another neurological hypersomnia) and to healthy controls.

Our main hypotheses were that night blackout was specific to $\mathrm{IH}$, distinct from dreamless sleep, and linked to sleep inertia in IH.

\section{Material and methods}

\subsection{Pilot and post-hoc studies}

The neurologists of the national reference center for rare hypersomnias in this university hospital regularly diagnose and follow up every year more than 1,000 patients with narcolepsy and $\mathrm{IH}$. After having noticed for the first time that patients with narcolepsy were frequent and proficient lucid dreamers (Dodet, Chavez, Leu-Semenescu, Golmard, \& Arnulf, 2015), they paid more attention to the experiences of the night in patients with rare hypersomnias during the regular, yearly interview with $\mathrm{IH}$ and narcolepsy patients. Therefore, they noticed some new symptoms in link with the night experience, that had gone unnoticed or not paid enough attention before, despite they were recurrently expressed by patients. This included either the feeling of "dreaming too much (that they named 'hyperonirism' in around $20 \%$ of the IH patients, not studied in the present article), or on the contrary, in a much larger percentage of IH patients, the complaint of what is now named 'night blackout'. Spontaneous reports included: "I put my head on the pillow and wake up the next morning with no recall of what has happened in between"; "I wake up in the morning with the feeling of having not experienced the nighttime elapsing, as if I had just put my head on the pillow when the alarm clock rings"; "I am in a coma during the night"; or "I sleep like a stone". Several patients named this symptom "a black out" in keeping with the experience reported by alcohol binge drinkers. A patient with IH named 
E. Chabani, et al.

this phenomenon "my black nights" (as opposed to "white night", which is the French term for sleepless night). Based on these reports obtained in $\mathrm{IH}$ patients during routine evaluations, the neurologists and scientists built the questions relative to night blackout in the questionnaire, using the exact wording of the IH patients. Eventually, a post-hoc checking was made when face to face discussing the understanding of some specific mental experiences (i.e., blank mind, deep sleep, night blackout) of the questionnaire with a panel of 20 new untreated $\mathrm{IH}$ patients during their $48 \mathrm{~h}$ sleep diagnosis; no major misunderstanding was found.

\subsection{Participants to the systematic study}

We consecutively recruited adult patients with IH and narcolepsy who had been diagnosed and followed in our sleep unit (a national reference center for rare hypersomnias in adult), using the list of patients diagnosed between 2014 and 2017. All patients agreed to take part in our study and signed a written consent. Patients received the questionnaire by email, ground mail, or during a visit in the sleep disorders unit. The study was approved by the local ethics committee (Comité de Protection des Personnes - lle de France 06). The patients were treated at time of completing the questionnaire, and their treatment at time of the questionnaire was collected. It was an auto-administered questionnaire and potentially ambiguous concepts as lucid dreams, automatic behaviors, nightmares, bad dreams and sleep-related hallucinations were defined in the questionnaire. It was made clear in the beginning of the questionnaire that it was a one-off questionnaire about dreams and sleeprelated experiences in general. The patients' sleep measures had been performed without any treatment, some months to 3 years before the questionnaire. They were retrospectively collected in the patients files. All patients had been previously diagnosed because they met 
E. Chabani, et al.

the following criteria: (1) complaint of excessive daytime sleepiness occurring daily for more than 3 months; and (2) central hypersomnia (narcolepsy and $\mathrm{IH}$ ), not better explained by another sleep disorder, medical or psychiatric condition, medication use or substance abuse, and behaviorally-induced insufficient sleep syndrome. Patients had completed a sleep log at diagnosis interview. They were separated into IH and narcolepsy groups. The patients with narcolepsy had been diagnosed according to a nighttime sleep time longer than 6 hours, followed by a mean daytime sleep latency lower than 8 minutes and two or more sleep onset REM periods during the multiple sleep latency test, which included 5 tests performed at 8:00, 10:00, 12:00, 14:00 and 16:00 (American Academy of Sleep Medicine, 2014). The patients with narcolepsy type 1 had clear-cut cataplexy or hypocretin levels lower than $110 \mathrm{pg} / \mathrm{mL}$ in the cerebrospinal fluid (Mignot et al., 2002). A few patients with narcolepsy type 2 (no cataplexy or hypocretin deficiency) were included too. Patients with IH had been monitored during a $48 \mathrm{~h}$ procedure as previously described, including a first night monitoring stopped at 06:30, followed by a multiple sleep latency test and followed again during the second night and day (totaling an 18 hour period) by an ad libitum sleep monitoring starting from $21: 00$ to $22: 00$ (ad libitum) to the next morning awakening, followed by an attempt to sleep again during a morning and an afternoon nap (Vernet \& Arnulf, 2009). The diagnosis of IH was met when patients had: (1) a mean sleep latency lower than 8 minutes and 0 or 1 sleep onset REM period during multiple sleep latency test; or (2) a total sleep time longer than $11 \mathrm{~h}$ during the long-term (18-19 hour long) sleep monitoring (American Academy of Sleep Medicine, 2014). The causes of secondary hypersomnia had been ruled out after psychiatric interview, neurological and physical examination and brain magnetic resonance imaging. All patients with narcolepsy and IH had a measure of the human leukocyte antigen (HLA) genotype DQB1*0602. Healthy controls 
E. Chabani, et al.

were recruited using a mailing list of unpaid, healthy volunteers for research led by the CNRS (Mailing list "Experiences" throughout the "Relais d'information en sciences de la cognition", www.risc.cnrs.fr/). Healthy controls completed the questionnaire. We excluded those who self-declared as suffering from any sleep disorder or those who scored higher than 10/24 on the Epworth sleepiness scale (Johns, 1991).

\subsection{Questionnaires}

The patients completed the series of questionnaires online or in a paper version only one time and in the French version. The main questionnaire (Supplemental data) was specifically elaborated to capture all kinds of night-related experiences (or their absence) in Part \#I, including: i) Dreaming (part A); ii) Thinking (part B); iii) Consciousness (part C); iv) Lucid dreaming, nightmares, dysphoric dreams and sleep-related hallucinations (part D). In Part \#II, there were questions on general sleep and sleep symptoms in the recent times. The questions about dreaming included the number of dreams (per night and per week, items $A 1$ and $A 2$ ), the easiness for recalling them in general (6 discrete choices, from an "easy recall" to "never any recall", item A3), whether dream recalls were fragmentary or complete (item A4), the variability of dream recall over time (from 1: "very regular" to 5: "very variable", item A5), the usual dream vividness (6 discrete choices, from 1: "extremely vivid" to 6: "very vague", item A6), following the terms of the questionnaire of Zadra (Zadra, 1996). Questions on weekly frequency of experiences were scored as “I don't know”, never, rarely (lower than 1/week), occasionally (1-2 times/week), frequently (3-4 times/week), almost all the time or all the time (5-7 times/week) for dreams containing bizarre (illogical, item A7), mundane (item A8), unusual (compared to wakeful life, item A9), brief images (item A10), as well as movie-like long scenario contents (item A11). Part B was about night 
E. Chabani, et al.

thinking, and was built for catching ruminations in insomnia patients: the results were not used here, as they did not pertain to the night blackout phenomenon. The part $C$ of the questionnaire contained questions (from "never" to "almost all the time", i.e., 5-7 times/week) about consciousness during the night, including difficulties "letting it go" (loosing consciousness) before falling asleep (item C1), perception of deep sleep (item C2), of night blackout (labelled as "do you wake up in the morning with the feeling of having not experienced the nighttime elapsing, as if you had just put your head on the pillow when the alarm clock rings ?", item C3), feeling of blank mind during sleep (item C4), feeling of totally loosing consciousness when sleeping (item C5), and feeling that the sleep mentation extended what can be recalled upon awakening (Item C6: The exact question was "Do you feel that your mental life when you sleep is richer than what you can report upon awakening"). In part D, using examples, we asked about the existence of lucid dreaming (item D1) as yes, no or uncertain, and their frequency (6 discrete choices from "less than once a year" to "every night") as well as the frequency of nightmares (item D2), bad dreams (item D3) and sleep-related hallucinations (item D4), with 6 discrete choices from "never" to "every night" plus "I don't know", plus two questions about hyperonirism (results not used here). The second part of the questionnaire was about routine sleep habits, including sleep times (during weekdays, weekend and vacations), naps (number, frequency and duration of naps), morning awakening (presence and duration of severe sleep inertia, feeling of being refreshed, need for and reaction to alarm clock, need to be awakened by someone else, difficulty awakening, time from alarm clock ringing to feeling totally awake, feeling foggy, displaying automatic and inappropriate behaviors upon awakening), daytime sleepiness and cataplexy (sudden, partial or complete, brief loss of muscle tone when telling a joke or laughing). The subjects completed the Epworth sleepiness scale (Johns, 1991), and the 
E. Chabani, et al.

Hospital Anxiety and Depression Rating Scale (Zigmond \& Snaith, 1983). The information about medical history, age at sleepiness onset, severe morning inertia (sleep drunkenness, as reported by the neurologist in charge), and treatment history (including treatment at time of completing the questionnaire) was collected in the medical file of the patients.

\subsection{Statistical analysis}

For all analyses, we used the R statistical programming language (version 3.4.1) and RStudio (an IDE for R, version 1.1.447, R Core Team 2018). Because questionnaire scores and sleep measures were not normally distributed, we used nonparametric tests and represented the distributions as median, first and third quartiles. The categorical variables were represented as proportions (percentages). Between-group differences involving more than two groups (comparison between $\mathrm{IH}$, narcolepsy and control groups) were examined using the KruskalWallis test, followed by post hoc Dunn's multiple comparisons test with a Bonferroni correction. Associations between categorical variables were tested using the Fisher's exact test and the Bonferroni method was also applied to adjust $\mathrm{P}$ values for multiple comparisons. Night blackout referred to answers to the question C3. To further investigate the night blackout in $\mathrm{IH}$, we assessed intra-group differences (subgroups with no or rare vs. frequent/permanent night blackout within the IH group) using the Wilcoxon-Mann-Whitney test for continuous variables, the Chi-squared test for categorical variables and the CochranArmitage test for trend (using the R package DescTools) for discrete scales. To pre-screen a subset of potential variables of interest, the $P$ values from multiple comparisons were adjusted using a less stringent correction with the Benjamini-Hochberg procedure, except for within $\mathrm{IH}$ group comparison of sleep measures because it was a retrospective, exploratory study. 
E. Chabani, et al.

\section{Results}

\subsection{Demographic and clinical characteristics of the sample}

The questionnaire was sent to 274 patients with $\mathrm{IH}$, among which 133 completed it, and to 238 patients with narcolepsy, among which 108 completed it (Table 1). There were no difference in the percentage of responders in each group, but patients with narcolepsy took longer than those with $\mathrm{IH}$ to answer the questionnaire. The 108 participants with narcolepsy included 91 (84\%) patients with narcolepsy type 1 and 17 (16\%) patients with narcolepsy type 2. There was a higher percentage of women in the IH than in the narcolepsy and healthy control groups. The age and education levels were not different between groups (note that the healthy controls were selected to match for age with the other groups). The score at the anxiety scale was higher in the $\mathrm{IH}$ than in the narcolepsy and control groups. The score at the depression scale was higher in the IH and narcolepsy groups than in the control group. Patients with IH slept longer than narcolepsy patients and controls during weekdays, weekends and holidays (Table 2). Narcolepsy patients slept longer than controls during weekdays. More patients with $\mathrm{IH}$ had difficulties waking up and felt unrest upon morning awakening than patients with narcolepsy and controls had, and it took them longer to be totally awake after awakening. Patients with narcolepsy were sleepier than those with $\mathrm{IH}$, and patients (with $\mathrm{IH}$ or narcolepsy) were sleepier than controls (whether considering the Epworth sleepiness score, the percent of subjects needing to nap, and the weekly nap frequency). However, more patients with $\mathrm{IH}$ complained of automatic behaviors than 
E. Chabani, et al.

narcolepsy patients and controls did. As expected, cataplexy was reported only in narcolepsy patients.

\subsection{Characteristics of dreaming and consciousness during night and sleep}

The dream recall frequency (per week and per night, upon awakening) was higher in the narcolepsy than in the $\mathrm{IH}$ and control groups (Table 3). The frequencies of short and long dreams were similar across groups. Regarding the dream content, patients with narcolepsy had the highest frequency of mundane and lucid dreams, followed by $\mathrm{IH}$ patients and then by controls. There was no between-group difference regarding the vivid, unusual and bizarre aspects of dream contents. Bad dreams were similarly frequent across groups, but patients with narcolepsy had more frequent nightmares.

In terms of consciousness during the night, all groups experienced similar weekly frequencies of "feeling of blank mind during the night", but "feeling of deep sleep" was more frequent in $\mathrm{IH}$ patients than in narcolepsy patients and controls. As for the night blackout (labelled as "how often do you wake up with the feeling of having not experienced the nighttime elapsing, as if you had just put your head on the pillow when the alarm clock rings ?"), as many patients with $\mathrm{IH}$ and with narcolepsy experienced it 3 to 4 nights per week (whereas it was exceptional in controls), but it was almost permanent (5 to 7 nights per week) in $24.2 \%$ of IH patients (vs. $11.7 \%$ of narcolepsy patients and $3.1 \%$ of control, a significant difference) (Table 3, Figure). Eventually, half of patients with IH had frequent or permanent night blackout. Consequently, the weekly frequencies of the night blackout and of complete loss of consciousness during sleep were higher in $\mathrm{IH}$ than in narcolepsy and 
E. Chabani, et al.

control groups. The feeling that sleep mentation, when not recalled, extended what could be recalled was similarly frequent across groups. The presence and frequency of night blackout was not different in patients with narcolepsy type 1 vs. type 2 (data not shown).

\subsection{Is the night blackout an equivalent to dreamless sleep?}

To address this question, we looked for an eventual overlap between the "non-dreamer" trait (and not the state) and the "frequent night blackout" (as a night blackout trait). The non-dreamers (subjects who scored " 0 " at the question on weekly dream recall frequency) were extracted in each group, and their answer to the question about night blackout was examined. Indeed, one may suppose that night blackout encompasses the absence of dream recall, whereas subjects could be dreamless but could perceive that they experience a sleep night. There were $5(5.5 \%)$ non-dreamers in the control group, $7(7.0 \%)$ in the narcolepsy group and $10(7.5 \%)$ in the $\mathrm{IH}$ group, a non-significant difference $(P=0.54)$. Among these 22 (6\%) non-dreamers, 3 had never experienced any night blackout (1 in the control group and 2 in the narcolepsy group), 4 had rare or occasional night blackout, 4 had frequent night blackout ( 1 in the $\mathrm{IH}, 2$ in the narcolepsy and 1 in the control group) and only 8 had permanent night blackout (6 in the $\mathrm{IH}[18.8 \%]$ and 2 in the narcolepsy groups). This rare, partial overlap indicated that dreamless sleep and night blackout were two different dimensions. There were no significant linear correlation between the dream recall frequency and the weekly frequency of night blackout in the 232 responders from the control and narcolepsy groups $(R=-0.09 ; P=0.13)$, but the two frequencies correlated in the $\mathrm{IH}$ group $(\mathrm{N}=132$ responders; $\mathrm{R}=-0.32 ; \mathrm{P}<0.001)$. 
E. Chabani, et al.

\subsection{Effect of drugs on night blackout}

Regarding drugs, 180 patients were taking sodium oxybate $(\mathrm{N}=25,10$ with $\mathrm{HI}$ and 15 with narcolepsy) and stimulants (modafinil, $\mathrm{N}=90$; methylphenidate, $\mathrm{N}=65$; pitolisant, $\mathrm{N}=32$; dextroamphetamine, $N=4$, including 32 patients on combined therapy), whereas 47 patients were intreated ( 22 with $\mathrm{IH}$ and 25 with narcolepsy). The information about treatment was missing in 14 patients. The frequency of night blackout was not different between treated and untreated patients $(P=0.54)$. Plus, $47 \%$ of untreated vs. $43 \%$ of treated patients had frequent night blackout $(P=0.62)$. In particular, the frequency of night blackout was not different between the 25 patients taking sodium oxybate (which may reduce the consciousness and the dream recall during the night) at nighttime and the 201 patients who did not take sodium oxybate $(P=0.56)$. There were $12 / 25(48 \%)$ patients with frequent night blackout among those taking sodium oxybate vs. 86/131 (66\%) among those not taking sodium oxybate $(P=0.09)$. There were no further differences within each hypersomnia subgroup. There was also no difference in terms of use of stimulants during daytime vs. the presence and frequency of night blackout.

\subsection{Factors associated with night blackout in idiopathic hypersomnia}

In order to find the factors associated with night blackout, we focused on the IH group, which contained the largest number of affected patients and was our primary group of interest. We excluded the patients with $\mathrm{IH}$ who experienced this phenomenon "from time to time" and contrasted the extremities of the spectrum, i.e., the $65 \mathrm{IH}$ patients with frequent or permanent night blackout (frequent night blackout) with the $43 \mathrm{IH}$ patients who reported absent or rare night blackout (without night blackout). There were no between-groups 
E. Chabani, et al.

differences for age, sex, education, age at disease onset, symptoms of depression and anxiety (Table 4), characteristics of usual sleep time and daytime sleepiness, and treatment. The characteristics of sleep inertia (in terms of frequency and duration) and of automatic behaviors were similarly high in both groups. The dream recall frequency was lower in the patients with than without frequent night blackout, but the contents of dreams and the frequency of bad dreams/nightmares were not different between groups (Table 5). Patients with frequent night blackout felt more frequently sleep as deep and mind as blank during the night than those without night blackout, but the feeling that sleep mentation exceeded what they could recall was similarly frequent between groups.

When looking at sleep measures previously obtained in the sleep laboratory, IH patients with frequent night blackout had a higher percentage of N3 sleep (Table 6). The other nighttime sleep measures (sleep duration during the habituation night, the ad libitum night and during long term monitoring, percentages of other sleep stages, sleep onset latency, sleep efficiency, arousal index, duration of wakefulness after sleep onset, periodic leg movements index, apnea-hypopnea index) and measures during the multiple sleep latency test did not differ between groups.

\section{Discussion}

In this large group of patients with IH and narcolepsy, as well as healthy controls, half of patients with $\mathrm{IH}$ experienced a frequent or permanent night blackout (resembling the 'blackout' experience reported by alcohol binge drinkers). This phenomenon was rarely reported by healthy controls, and reported by a lower proportion of patients with narcolepsy (another central disorder of hypersomnolence), and at a lower weekly 
E. Chabani, et al.

frequency. The IH patients with frequent/permanent night blackout had a lower dream recall frequency, felt more often sleep as deep and mind as blank during the night, and had a higher proportion of N3 sleep than IH patients without night blackout, but no other clinical, treatment or sleep difference, and no greater sleep inertia.

\subsection{Characteristics of the night blackout}

To the best of our knowledge, the experience of night blackout had not been previously described in the literature. Instead, most studies have focused on absence of dream recall, whether spontaneously (Pagel, 2003) or after a posterior stroke (Bischof \& Bassetti, 2004), but did not describe nights without any conscious report. In our study, the night blackout was not restricted to an absence of dream recall, although patients with night blackout phenotype had a lower dream recall frequency than those without. Plus, the night blackout was not equivalent to dreamless sleep, because the proportion of non-dreamers $(6 \%$ of the whole sample) and of patients with permanent night blackout (18.75\%) were different, and overlapped only in one third of the subjects.

The absence of consciousness of the night encompasses not only the absence of dreams, but something larger, i.e., a feeling of absence of thoughts and conscious experiences during the night (which corresponds here to the total sleep period, which includes sleep time plus periods of wakefulness after sleep onset, awakenings and arousals). The patients with frequent/permanent night blackout felt more frequently their nocturnal mind as "blank", suggesting they lost not only the dream recall and dream experience recall, but also their phenomenal consciousness experience. The existence of a phenomenal consciousness during dreamless sleep was suggested by Windt et al. (2015) and named "selfless states and contentless sleep", as the minimal state of consciousness that one can experience during 
E. Chabani, et al.

sleep. This state would be sufficient for feeling that some amount of time has elapsed, as a temporal experience in the form of a phenomenal 'now' (J. M. Windt, 2015). These authors argue that it is unlikely that sleep, outside dreaming experiences, is uniformly unconscious and therefore that it is unlikely that sleep result on an experience of a 'nothing' even when no dream are recalled. Indeed they remark that numerous cognitive processes occurring during the night and sleep must be associated with some kind of conscious experience (J. Windt, Nielsen, \& Thompson, 2016) and mainly that being asleep is not the absence of being (supposing, at least, a phenomenal experience of subjective temporality). Here we suggest that even this minimal consciousness can disappear in IH patients with night blackout, to the point that even preconscious cognitive processes during sleep do not lead to any recall (Nielsen, 2000; J. Windt et al., 2016) or sense of duration. However, it would seem difficult to claim that these patients with $\mathrm{IH}$ do not have any cognitive process during sleep and night, even if they present a total absence of conscious experience of their nights (including the time having elapsed from sleep onset to sleep offset).

\subsection{Is the night blackout a state or a trait?}

The night blackout was reported as 'occasional' in half of healthy controls, suggesting that this absence of experience is common but inconstant in the general population. It may also apply to part of the night and not all night, which has not been asked here. In contrast, $24.2 \%$ of $\mathrm{IH}$ patients reported a night blackout occurring on a nightly basis and $25 \%$ on a frequent basis. It suggests that the frequent night blackout (as a trait) is prevalent in $\mathrm{IH}$ and, to a much lesser degree, in narcolepsy (another disorder of hypersomnolence). The night blackout was first identified via face to face interviews with IH patients, performed by neurologists experienced with central hypersomnias during routine visits, and the 
E. Chabani, et al.

questionnaire was later developed based on the IH patients wordings, so that we cannot be sure that the narcolepsy patients and controls who ticked having some nights with night blackout on a written questionnaire have exactly the same kind of night blackout as reported by IH patients (similarly, cataplexy can be reported occasionally on questionnaires by non-narcoleptic patients or healthy controls, whereas it is probably not cataplexy). To avoid this potential issue, we restricted the analysis of the determinants of night blackout to the group of $\mathrm{IH}$ patients. Patients with $\mathrm{IH}$ are characterized by excessive daytime sleepiness, prolonged nocturnal sleep and difficulty to wake up (severe morning inertia). One may wonder whether some of these clinical features influence the night blackout. Notably, the IH patients with and without frequent/permanent night blackout had similar daytime sleepiness levels (measured as a subjective sleepiness score, need for naps and sleep onset latency during daytime tests) as well as similar total sleep times, suggesting that the severity of sleepiness does not play a major role in this experience.

\subsection{Is sleep too deep in patients with night blackout?}

Here, IH patients with frequent/permanent night blackout had higher N3 sleep percentages (as retrospectively collected in their previous sleep monitoring) than those without night blackout. It was the unique sleep marker associated with the night blackout. Of interest, N3 sleep (which is also called deep slow wave sleep) is associated with a decreased brain connectivity during sleep (Massimini et al., 2005). Specifically, the slow wave (with its associated neuronal 'off' periods) has been shown to lead to a breakdown in cortico-cortical connectivity, a theoretical prerequisite for the generation of conscious experiences (Tononi, 2008). There are lower (60\%, but not $0 \%)$ reports of conscious experiences upon awakening from N3 sleep in normal subjects than upon awakening from N2 sleep (80\%), from REM 
E. Chabani, et al.

sleep (90\%) and from N1 sleep (100\%) (F Siclari, LaRocque, Postle, \& Tononi, 2013). Plus, absence of dream reports from $50 \%$ of NREM sleep awakenings are associated with local changes in the surface EEG (slower delta waves and slower spindles), suggesting that the capacity of the brain to generate experiences during sleep is reduced in the presence of neuronal off-states in posterior and central brain regions activities (F. Siclari, Bernardi, Cataldi, \& Tononi, 2018). However, the N3 sleep represents a limited part of the complete sleep and night experiences, hence the small increase in N3 sleep in patients with vs. without frequent/permanent night blackout is not sufficient to imagine that this complete loss of consciousness across the full night results from the major breakdown of cortical connectivity in N3 (and even N2) sleep. It will be necessary in the future to directly measure and compare the cortico-cortical connectivity using EEG and functional brain imaging during sleep (especially in the posterior areas) in IH patients with vs. without night blackout to support this hypothesis.

\subsection{Are arousals too infrequent for encoding the night experience?}

Surprisingly, the index of arousals and awakenings were similar in IH patients with and without night blackout. Arousals are brief (lasting 3 to $15 \mathrm{~s}$ ) intrusions of wakefulness into sleep, associated with a stereotypic thalamic activity and a heterogeneous cortical activity (Peter-Derex, Magnin, \& Bastuji, 2015). These normal arousal events may contribute to encoding the previous sleep and night experiences, and their rarefaction may reduce the opportunities to encode these experiences. Longer awakenings in the general population are associated with a higher probability of encoding the previous dreams or conscious experience (Eichenlaub, Bertrand, Morlet, \& Ruby, 2014; Koulack \& Goodenough, 1976). However, one may note that time spent awake during the night and number of awakenings 
E. Chabani, et al.

(which are longer than arousals) per hour were not different in IH patients with vs. without frequent/permanent night blackout. All in all, this suggests that the night blackout as a trait is dependent on other factors than impaired opportunities to encode the previous experiences. However, here the number and duration of arousals (collected months before the questionnaire) were not directly contrasted with the immediate feeling of night blackout the next morning. Plus, high density EEG, stereoEEG or brain functional imaging may in the future identify some subtle changes in IH arousals, such as local sleep (Flamand et al., 2018; Vyazovskiy et al., 2011), which may impair the encoding of previous experiences.

\subsection{Is there any defect in encoding the experience upon awakening?}

There might be no phenomenal experience during sleep in subjects with night blackout, or there may be a phenomenal experience which is not encoded as so upon nocturnal awakenings and retrieved upon morning awakening. Difficulty in waking up is a major characteristic of $\mathrm{IH}$, which culminates with the pathognomonic symptom of 'sleep drunkenness', much severely than in narcolepsy or in normal controls (Trotti, 2017; Vernet et al., 2010). Here, as many as $81 \%$ of patients with IH did not hear the alarm clock, or heard it but could not be totally awake and stand up, and resumed immediately sleep, whether at morning awakening or after naps. The sleep drunkenness is an extreme form of the normal sleep inertia, which corresponds to an impaired (but progressively restored) cognitive performance and persistent sleepiness at the transition between sleep and wakefulness in normal subjects (Tassi \& Muzet, 2000; Trotti, 2017). This state lasts from $3 \mathrm{~min}$ to more than 30 min from awakening in normal subjects (Tassi et al., 1992). It is associated with anterior to posterior graded activation in EEG and in cerebral blood flow in functional brain imaging (Balkin et al., 2002; Marzano et al., 2011). In our study, the night blackout was 
E. Chabani, et al.

dramatically more frequent (and quite specific as a trait) in patients with IH (who frequently suffer from sleep drunkenness) than in patients with narcolepsy. But its presence and frequency within the $\mathrm{IH}$ group, as well as the duration of morning inertia, did not differ between patients with and without night frequent/permanent blackout. One may conclude that the severe morning inertia could not be responsible for erasing or not encoding the experiences from the night. Similarly, the use of sodium oxybate treatment at nighttime in narcolepsy and IH (Leu-Semenescu, Louis, \& Arnulf, 2016) may induce some black out phenomenon, as this is a form of gammahydroxybutyrate (Maitre, 1997). However, this drug was rarely used in the patients groups, and did not influence the presence and frequency of night blackout.

\subsection{How to further investigate the mechanisms of the night blackout?}

All in all, these preliminary, retrospective results suggest that the night blackout is not associated with (and possibly caused by) a lower possibility (lower arousal index) and a lower cognitive ability (longer and more marked morning sleep inertia, use of sodium oxybate) to encode or retrieve the previous experiences. The exact mechanisms remain to be determined, and may include EEG spectral analysis contrasting temporal and spatial frequency as well as connectivity (e.g., coherence and causality) between IH patients with and without night blackout. Ideally, these groups may be contrasted during wakefulness and sleep using functional brain imaging. In normal subjects having undergone sequential functional brain imaging upon awakening, it was shown that the increased activity within the thalamus, the anterior cingular cortex and the prefrontal cortex was associated with dissolution of sleep inertia and restored consciousness upon awakening (Balkin et al., 2002). One may study whether this network is impaired in IH patients with frequent/permanent 
E. Chabani, et al.

night blackout. Functional brain imaging has been recently performed in 13 patients with IH during wakefulness, with results suggesting that patients with $\mathrm{IH}$ have decreased activity in the prefrontal cortex during wakefulness (as if they had some local sleep) compared to healthy controls, in proportion with their level of daytime sleepiness (Boucetta et al., 2017). Furthermore, one may test whether IH patients with frequent night blackout could still interact with their environment during sleep, using auditory stimulation (with simple and complex paradigms, such as the odd ball paradigm) and event-related potentials. One may also try to differentiate night blackout from other nebulous experiences such as "white dreams", defined either as a dream experience without the ability to recall it (F Siclari et al., 2017) or a low quality experience (Fazekas, Nemeth, \& Overgaard, 2019). For this purpose, serial probing of conscious experiences upon awakenings are warranted in $\mathrm{IH}$ patients with permanent night blackout, as it has been performed in healthy subjects. These series of experiments will help determining whether $\mathrm{IH}$ patients with permanent night blackout experience a kind of "coma" each night, assessing the subjective impression of having slept via questions like "Were you asleep or awake?", the time awareness using questions like "How much time has elapsed since last moment we spoke?", the quality of conscious experience (lower quality experience than controls) and if subjects with blackout cannot encode their nocturnal experiences (more frequent 'white dreams' than controls). In addition, studying the level and quality of consciousness during daytime wakefulness (e.g., proclivity to daydreaming, vividness of mental imagery) in $\mathrm{IH}$ patients with and without night blackout would help to better qualify how they built and encode their spontaneous conscious experiences (Fazekas et al., 2019).

\subsection{Limitations}


E. Chabani, et al.

There are several limitations in this study, including the long (one month to 3 years) time elapsed between the sleep study and the questionnaire. Idiopathic hypersomnia is a rare disorder, rendering difficult a prospective study of consciousness immediately after sleep monitoring in a large group of patients. An immediate, face to face study could be planned in the future, now that the night blackout has been identified. The questionnaire refers to a long period of time, so that memory problem could have hamper the answers. The questionnaires were sent to subjects, and not face-to face administered, which may limit the fine comprehension of some questions about consciousness. Some protections were however taken against this bias, including the development of the questionnaire with patients (using their wordings), the inclusion of some examples of sleep mentation, and the face to face post-hoc checking of their understanding in a small group of IH patients. Plus, the questionnaire was completed in the same conditions by all subjects and groups, which ensures some homogeneity.

\section{Conclusions}

This study provides evidences that the night blackout is a new form of contentless sleep and night, which encompasses not only dreamless sleep and "selfless states and contentless sleep", but also the absence of consciousness that time has elapsed from sleep onset to sleep offset (the phenomenal "now"), which may resemble a kind of coma. This night blackout follows a spectrum of severity and frequency from healthy controls (who rarely experience it), to narcolepsy and then IH patients, which have the most consistent and pure form. The phenomenon is favored but not totally determined by increased slow wave sleep amounts, but not by arousability and sleep inertia, when retrospectively studying the sleep 
E. Chabani, et al.

measures. Patient with $\mathrm{IH}$ and night blackout provide a new, extreme model to study the vanishing of conscious experience during sleep.

\section{References}

American Academy of Sleep Medicine. (2014). The international Classification of Sleep Disorders, 3rd edition. Darien, IL: American Academy of Sleep Medicine.

Arnulf, I., Leu-Semenescu, S., \& Dodet, P. (2019). Precision Medicine for Idiopathic Hypersomnia. Sleep Med Clin, 14(3), 333-350.

Balkin, T., Braun, A., Wesensten, N., Jeffries, K., Varga, M., Baldwin, P., Belenky, G., \& Herscovitch, P. (2002). The process of awakening: a PET study of regional brain activity patterns mediating the re-establishment of alertness and consciousness. Brain, 125, 23082319.

Bischof, M., \& Bassetti, C. L. (2004). Total dream loss: a distinct neuropsychological dysfunction after bilateral PCA stroke. Ann Neurol, 56(4), 583-586.

Boucetta, S., Montplaisir, J., Zadra, A., Lachapelle, F., Soucy, J. P., Gravel, P., \& Dang-Vu, T. T. (2017). Altered Regional Cerebral Blood Flow in Idiopathic Hypersomnia. Sleep, 40(10).

Dodet, P., Chavez, M., Leu-Semenescu, S., Golmard, J., \& Arnulf, I. (2015). Lucid dreaming in narcolepsy. Sleep, 38, 487-497.

Eichenlaub, J. B., Bertrand, O., Morlet, D., \& Ruby, P. (2014). Brain reactivity differentiates subjects with high and low dream recall frequencies during both sleep and wakefulness. Cereb Cortex, 24(5), 1206-1215.

Fazekas, P., Nemeth, G., \& Overgaard, M. (2019). White dreams are made of colours: What studying contentless dreams can teach about the neural basis of dreaming and conscious experiences. Sleep Med Rev, 43, 84-91. 
E. Chabani, et al.

Flamand, M., Boudet, S., Lopes, R., Vignal, J. P., Reyns, N., Charley-Monaca, C., PeterDerex, L., \& Szurhaj, W. (2018). Confusional arousals during non-rapid eye movement sleep: evidence from intracerebral recordings. Sleep, 41(10).

Johns, M. H. (1991). A new method for measuring daytime sleepiness: the Epworth Sleepiness Scale. Sleep, 14, 540-545.

Koulack, D., \& Goodenough, D. (1976). Dream recall and dream recall failure: an arousalretrieval model. Psychol Bull, 83, 975-984.

Leu-Semenescu, S., Louis, P., \& Arnulf, I. (2016). Benefits and risk of sodium oxybate in idiopathic hypersomnia versus narcolepsy type 1: a chart review. Sleep Med, 7, 38-44.

Maitre, M. (1997). The gamma-hydroxybutyrate signalling system in brain: organisation and functional implications. Progr Neurobiol, 51, 337-361.

Marzano, C., Ferrara, M., Mauro, F., Moroni, F., Gorgoni, M., Tempesta, D., Cipolli, C., \& De Gennaro, L. (2011). Recalling and forgetting dreams: theta and alpha oscillations during sleep predict subsequent dream recall. J Neurosci, 31(8), 6674-6683.

Massimini, M., Ferrarelli, F., Huber, R., Esser, S. K., Singh, H., \& Tononi, G. (2005). Breakdown of cortical effective connectivity during sleep. Science, 309(5744), 2228-2232.

Mignot, E., Lammers, G. J., Ripley, B., Okun, M., Nevsimalova, S., Overeem, S., Vankova, J., Black, J., Harsh, J., Bassetti, C., Schrader, H., \& Nishino, S. (2002). The role of cerebrospinal fluid hypocretin measurement in the diagnosis of narcolepsy and other hypersomnias. Arch Neurol, 59(10), 1553-1562.

Nielsen, T. A. (2000). A review of mentation in REM and NREM sleep: "covert" REM sleep as a possible reconciliation of two opposing models. Behav Brain Sci, 23(6), 851-866; discussion 904-1121.

Noreika, V., Valli, K., Lahtela, H., \& Revonsuo, A. (2009). Early-night serial awakenings as a new paradigm for studies on NREM dreaming. Int J Psychophysiol, 74(1), 14-18.

Pagel, J. F. (2003). Non-dreamers. Sleep Med, 4(3), 235-241.

Peter-Derex, L., Magnin, M., \& Bastuji, H. (2015). Heterogeneity of arousals in human sleep: A stereo-electroencephalographic study. Neuroimage, 123, 229-244. 
E. Chabani, et al.

Siclari, F., Baird, B., Perogamvros, L., Bernardi, G., LaRocque, J., Riedner, B., Boly, M., Postle, B., \& Tononi, G. (2017). The neural correlates of dreaming. Nature Neurosci, 20(6), 872-878.

Siclari, F., Bernardi, G., Cataldi, J., \& Tononi, G. (2018). Dreaming in NREM Sleep: A HighDensity EEG Study of Slow Waves and Spindles. J Neurosci, 38(43), 9175-9185.

Siclari, F., LaRocque, J., Postle, B., \& Tononi, G. (2013). Assessing sleep consciousness within subjects using a serial awakening paradigm. Front Psychol, 4, 542.

Tassi, P., \& Muzet, A. (2000). Sleep inertia. Sleep Med Rev, 4(4), 341-353.

Tassi, P., Nicolas, A., Dewasmes, G., Eschenlauer, R., Ehrhart, J., Salame, P., Muzet, A., \& Libert, J. P. (1992). Effects of noise on sleep inertia as a function of circadian placement of a one-hour nap. Percept Mot Skills, 75(1), 291-302.

Trotti, L. (2017). Waking up is the hardest thing I do all day: Sleep inertia and sleep drunkenness. Sleep Med, 35, 78-84.

Vernet, C., \& Arnulf, I. (2009). Idiopathic hypersomnia with and without long sleep time: a controlled series of 75 patients. Sleep, 32(6), 752-759.

Vernet, C., Leu-Semenescu, S., Buzare, M., \& Arnulf, I. (2010). Subjective symptoms in idiopathic hypersomnia: beyond excessive sleepiness. J Sleep Res, 19(4), 525-534.

Vyazovskiy, V., Olcese, U., Hanlon, E., Nir, Y., Cirelli, C., \& Tononi , G. (2011). Local sleep in awake rats. Nature, 472, 443-447.

Windt, J., Nielsen, T., \& Thompson, E. (2016). Does consciousness disappear in dreamless sleep? Trends Cogn Sci, 20(12), 871-882.

Windt, J. M. (2015). Just in time - dreamless sleep experience as pure subjective temporality. In T. Metzinger \& J. M. Windt (Eds.), Open MIND, Philosophy and the Mind Sciences in the 21st Century (pp. 1571-1604). Cambridge, MA: MIT Press.

Zadra, A. L. (1996). Dimensions of repetition and negative affect in dreams and their relation to psychological well-being. (Vol. .57(3-B), 217). Montreal: National Library of Canada = Bibliothèque Nationale Du Canada. 
E. Chabani, et al.

Zigmond, A. S., \& Snaith, R. P. (1983). The hospital anxiety and depression scale. Acta Psychiatr Scand, 67(6), 361-370. 
E. Chabani, et al.

Legend of the Figure: Weekly frequency of night blackout among patients with central hypersomnias (idiopathic hypersomnia and narcolepsy) as well as healthy controls. The darkest colors denote higher frequencies. 
E. Chabani, et al.

Table 1 - Demographic and clinical characteristics of patients with idiopathic hypersomnia and narcolepsy and of healthy controls

\begin{tabular}{|c|c|c|c|c|c|}
\hline & $\begin{array}{c}\text { Idiopathic } \\
\text { hypersomnia }\end{array}$ & Narcolepsy & Control & $P$ value & $\begin{array}{l}\text { Corrected } \\
\text { P value }\end{array}$ \\
\hline $\begin{array}{l}\text { Contacted } \\
\text { patient, } \mathrm{n}\end{array}$ & 274 & 256 & NA & NA & \\
\hline Responders, \% & 48.5 & 42.2 & NA & 0.163 & \\
\hline $\begin{array}{l}\text { Time to answer, } \\
\text { week }\end{array}$ & $3[1 ; 21]^{a}$ & $31.5[10 ; 63]^{c}$ & $4.5[1 ; 10]$ & $<0.001 *$ & $<0.001^{*}$ \\
\hline Participants, n & 133 & 108 & 128 & NA & \\
\hline Sex, female \% & $78.2^{a, b}$ & 60.2 & 62.5 & $0.004^{*}$ & $0.008^{*}$ \\
\hline $\begin{array}{l}\text { Education level, } \\
1-7\end{array}$ & $7[6 ; 7]^{b}$ & $7[6 ; 7]^{c}$ & $7[6 ; 7]$ & $0.008^{*}$ & $0.013^{*}$ \\
\hline Age at study, year & $31[25 ; 43]$ & $29[23 ; 40]^{c}$ & $25[22.8 ; 38.3]$ & 0.053 & 0.053 \\
\hline $\begin{array}{l}\text { Age at disease } \\
\text { onset, year }\end{array}$ & $\begin{array}{c}18.5[15 ; \\
32.25]\end{array}$ & $16[13 ; 25]$ & NA & $0.019 *$ & $0.026^{*}$ \\
\hline \multicolumn{6}{|c|}{ Hospital Anxiety and Depression Rating Scale, score 0-42 } \\
\hline Anxiety, 0-21 & $9[6 ; 11]^{b}$ & $8[6 ; 11.25]$ & $7[5 ; 9]$ & $0.029 *$ & $0.034 *$ \\
\hline Depression, 0-21 & $6[3 ; 9]^{b}$ & $6[3 ; 8]^{c}$ & $3[2 ; 6]$ & $<0.001^{*}$ & $<0.001^{*}$ \\
\hline
\end{tabular}

* Significant $p$-values $(<0.05)$ and $p$-values corrected with the Benjamini-Hochberg procedure. Post-hoc comparisons were significant when $\mathrm{p}<0.0166$ (after Bonferroni 
E. Chabani, et al.

correction) for a difference between ${ }^{\mathrm{a}}$ idiopathic hypersomnia and narcolepsy groups;

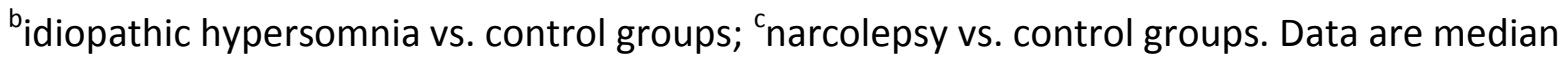
$\left[1^{\text {rst }}-3^{\text {rd }}\right.$ quartile $]$. NA: not applicable. 
E. Chabani, et al.

Table 2 - Sleep symptoms and clinical characteristics in patients with idiopathic hypersomnia, and narcolepsy and in healthy controls

\begin{tabular}{|c|c|c|c|c|c|}
\hline & $\begin{array}{c}\text { Idiopathic } \\
\text { hypersomnia }\end{array}$ & Narcolepsy & Control & $P$ value & $\begin{array}{c}\text { Corrected } \\
\text { P value }\end{array}$ \\
\hline Number of patients & 133 & 108 & 128 & & \\
\hline \multicolumn{6}{|c|}{ Nighttime sleep time, $\min$} \\
\hline During weekdays & $480[420 ; 540]^{a, b}$ & $480[390 ; 480]^{c}$ & $420[390 ; 480]$ & $<0.001^{*}$ & $<0.001^{*}$ \\
\hline During weekend & $600[540 ; 720]^{a, b}$ & $540[480 ; 600]$ & $540[480 ; 540]$ & $<0.001 *$ & $<0.001^{*}$ \\
\hline During holidays & $600[540 ; 720]^{a, b}$ & $540[480 ; 600]$ & $540[480 ; 570]$ & $<0.001^{*}$ & $<0.001^{*}$ \\
\hline
\end{tabular}

Morning sleep inertia

$\begin{array}{lccccc}\begin{array}{l}\text { Difficulty to wake up } \\ \%\end{array} & 81.2^{\mathrm{a}, \mathrm{b}} & 56.5 & 50 & <0.001^{*} & <0.001^{*} \\ \begin{array}{l}\text { Feeling unrest upon } \\ \text { morning awakening } \\ \%\end{array} & 73.7^{\mathrm{a}, \mathrm{b}} & 54.6^{\mathrm{c}} & 25.8 & <0.001^{*} & <0.001^{*} \\ & & & & \\ \text { Time waking up, } \min & 30[10 ; 90]^{\mathrm{a}} & 10[0 ; 30]^{\mathrm{c}} & 10[0 ; 30] & <0.001^{*} & <0.001^{*}\end{array}$

Daytime sleepiness

$\begin{array}{lccccc}\text { Epworth score, } 0-24 & 15[13 ; 18]^{\mathrm{b}} & 17[13 ; 19]^{\mathrm{c}} & 6[4 ; 8] & <0.001^{*} & <0.001^{*} \\ \text { Naps, \% patients } & 84.8^{\mathrm{a}, \mathrm{b}} & 97.2^{\mathrm{c}} & 61.7 & <0.001^{*}<0.001^{*}\end{array}$


E. Chabani, et al.

Naps frequency, $\quad 2[0.5 ; 4]^{\mathrm{a}, \mathrm{b}} \quad 5.5[2 ; 9.25]^{\mathrm{c}} \quad 0.7[0 ; 2] \quad<0.001^{*}<0.001^{*}$
n/week Naps duration, min $\quad 60[42.5 ; 120]^{a} \quad 30[20 ; 60]^{c} \quad 37.5[21.88 ; 60]<0.001^{*} \quad<0.001^{*}$ $\begin{array}{lllll}\text { Automatic } & 36.1^{\mathrm{a}, \mathrm{b}} & 14.8 & 10.16 & <0.001^{*}<0.001^{*}\end{array}$ behaviors, \% Cataplexy,\% $0^{\mathrm{a}}$ $83^{c}$ $0 \quad<0.001^{*}<0.001^{*}$

\footnotetext{
* Significant $\mathrm{P}$ values $(<0.05)$ and $\mathrm{P}$ values corrected with the Benjamini-Hochberg procedure.
}

Post-hoc comparisons were significant when $\mathrm{P}<0.0166$ (after Bonferroni correction) for a difference between ${ }^{a}$ idiopathic hypersomnia and narcolepsy groups; ${ }^{b}$ idiopathic hypersomnia and control groups; ${ }^{c}$ narcolepsy and control groups. Data are median $\left[1^{\text {rst }}-3^{\text {rd }}\right.$ quartile $]$. 
E. Chabani, et al.

Table 3 - Characteristics of dreams and consciousness during the night in patients with idiopathic hypersomnia and narcolepsy, and in healthy controls

\begin{tabular}{llcc}
\hline $\begin{array}{l}\text { Idiopathic } \\
\text { hypersomnia }\end{array}$ & Narcolepsy & Control & P value \\
& $\begin{array}{l}\text { Corrected } \\
\text { P value }\end{array}$ \\
\hline
\end{tabular}

\section{Dreaming characteristics}

\begin{tabular}{|c|c|c|c|c|c|}
\hline $\begin{array}{l}\text { Dream recall frequency, } \\
\text { n/week }\end{array}$ & $3[1.5 ; 5]^{\mathrm{a}}$ & $5[3 ; 7]^{c}$ & $3[1.5 ; 5]$ & $<0.001^{*}$ & $<0.001^{*}$ \\
\hline $\begin{array}{l}\text { Dream recall frequency, } \\
n / \text { day }\end{array}$ & $1[1 ; 1.5]^{\mathrm{a}}$ & $1.5[1 ; 2]^{\mathrm{c}}$ & $1[1 ; 1.5]$ & $<0.001^{*}$ & $<0.001^{*}$ \\
\hline Brief images, n/week & $0.9[0 ; 1.5]$ & $0.9[0.9 ; 1.5]$ & $0.9[0 ; 1.5]$ & 0.052 & 0.087 \\
\hline Long scenarios, n/week & $1.5[0.9 ; 3.5]$ & $2.5[0.9 ; 3.5]$ & $1.5[0.9 ; 3.5]$ & 0.159 & 0.199 \\
\hline $\begin{array}{l}\text { Mundane dreams, } \\
\text { n/week }\end{array}$ & $0.9[0.9 ; 3.5]^{\mathrm{a}}$ & $1.5[0.9 ; 3.5]^{c}$ & $0.9[0.9 ; 1.5]$ & $<0.001 *$ & $<0.001^{*}$ \\
\hline Vivid dreams, 1-6 & $5[4 ; 5]$ & $4.5[4 ; 5]$ & $4[4 ; 5]$ & 0.091 & 0.136 \\
\hline Bizarre dreams, n/week & $1.2[0.9 ; 1.5]$ & $1.5[0.9 ; 3.5]$ & $1.5[0.9 ; 1.5]$ & 0.193 & 0.222 \\
\hline Lucid dreams, n/month & $0.3[0.05 ; 3]^{\mathrm{a}}$ & $3[0.3 ; 7]^{c}$ & $0.3[0.05 ; 3]$ & $<0.001^{*}$ & $<0.001^{*}$ \\
\hline Bad dreams, n/month & $1[0.12 ; 10]$ & $3[0.25 ; 5]$ & $1[0.25 ; 3]$ & 0.129 & 0.176 \\
\hline Nightmares, n/month & $0.25[0.12 ; 3]^{\mathrm{a}}$ & $0.25[0.12 ; 5]^{\mathrm{c}}$ & $0.25[0.05 ; 1]$ & $0.003^{*}$ & $0.007^{*}$ \\
\hline
\end{tabular}

Consciousness during the night

$\begin{array}{llllll}\text { Blank mind during sleep, } \quad 0.9[0 ; 3.5] & 0.9[0 ; 1.5] & 0.9[0 ; 1.5] & 0.418 & 0.447\end{array}$

$\mathrm{n} /$ week

Feeling that sleep is $\quad 6[1.5 ; 6]^{\mathrm{a}} \quad 1.5[0.9 ; 3.5] \quad 3.5[1.5 ; 4.1]<0.001^{*} \quad<0.001^{*}$ deep, n/week

Night blackout during the night 
E. Chabani, et al.

\begin{tabular}{|c|c|c|c|c|c|}
\hline Responders, $\mathrm{n}$ & 132 & 105 & 128 & & \\
\hline $\begin{array}{l}\text { Blackout 3-4 } \\
\text { nights/week, \% of } \\
\text { responders }\end{array}$ & $25.0^{\mathrm{b}}$ & $22.2^{c}$ & 13.3 & $<0.001^{*}$ & $<0.001^{*}$ \\
\hline $\begin{array}{l}\text { Blackout 5-7 nights/week } \\
\% \text { of responders }\end{array}$ & 24.1 & 11.1 & 3.1 & $<0.04^{*}$ & $<0.057$ \\
\hline $\begin{array}{l}\text { Blackout 3-7 } \\
\text { nights/week, \% of } \\
\text { responders }\end{array}$ & $49.1^{\mathrm{a}, \mathrm{b}}$ & $33.3^{c}$ & 16.4 & $<0.001^{*}$ & $<0.001^{*}$ \\
\hline Blackout feeling, n/week & $1.5[0.9 ; 3.5]^{a, b}$ & $0.9[0 ; 3.5]$ & $0.9[0.9 ; 1.5]$ & $0.001 *$ & $<0.001^{*}$ \\
\hline $\begin{array}{l}\text { Complete loss of } \\
\text { consciousness, n/week }\end{array}$ & $1.5[0.9 ; 6]^{\mathrm{a}}$ & $0.9[0 ; 3.5]$ & $1.5[0.9 ; 3.5]$ & $0.029 *$ & 0.054 \\
\hline $\begin{array}{l}\text { Sleep mentation extends } \\
\text { what can be recalled, } \\
\text { n/week }\end{array}$ & $1.5[0 ; 3.5]$ & $1.5[0 ; 3.5]$ & $1.5[0.9 ; 1.5]$ & 0.781 & 0.781 \\
\hline
\end{tabular}

* Significant $P$ values $(<0.05)$ and $P$ values corrected with the Benjamini-Hochberg procedure. Post-hoc comparisons were significant when $\mathrm{P}<0.0166$ (after Bonferroni correction) for a

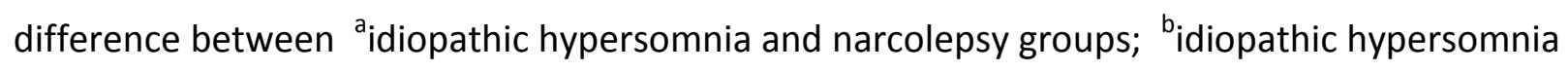
vs. control groups; ${ }^{c}$ patients with narcolepsy vs. control groups. Data are median $\left[1^{\text {rst }}-3^{\text {rd }}\right.$ quartile]. 
E. Chabani, et al.

Table 4 - Demographic and clinical characteristics in patients with idiopathic hypersomnia, with frequent/permanent night blackout and without night blackout

\begin{tabular}{lccc}
\hline $\begin{array}{l}\text { Patients with idiopathic } \\
\text { Hypersomnia }\end{array}$ & $\begin{array}{c}\text { With frequent or } \\
\text { permanent night }\end{array}$ & Without night & P value \\
& blackout & & \\
& 65 & 43 & \\
\hline Number of patients & 75.4 & 79.1 & 0.83 \\
Sex, female \% & $7[6 ; 7]$ & $7[6 ; 7]$ & 0.63 \\
Education level, $1-7$ & $33[27 ; 47]$ & $31[24.5 ; 39]$ & 0.26 \\
Age at study time, y & $18[15 ; 27.5]$ & $18[15 ; 34]$ & 0.76 \\
Age at disease onset, y & & & \\
\end{tabular}

Hospital Anxiety and Depression Rating Scale, score 0-42

Anxiety, 0-21

Depression, 0-21

Usual nighttime sleep time, $\min$

During weekdays

$480[432 ; 540]$
During weekend

During holidays

Sleep drunkenness

Morning sleep inertia, \%

75

86.2

69.2

$600[540 ; 720]$

$600[540 ; 720]$

$600[540 ; 750]$

Difficulty to wake up, \%

Feeling unrest upon morning awakening, \%
$480[420$;

562.5]

0.70

$9[7 ; 10] \quad 0.67$

$7[4 ; 9.5] \quad 0.28$

$600[540 ; 720] \quad 0.92$ 
E. Chabani, et al.

Time for fully being awake, min

$60[10 ; 90]$

$30[30 ; 90]$

0.97

Daytime sleepiness

Epworth sleepiness score, 0-24

$14[11 ; 18]$

$15[13 ; 18]$

0.23

Naps frequency, $n / w$

$2[0.21 ; 3.5]$

$1.5[0.4 ; 4.75]$

0.97

Naps duration, min

$60[45 ; 120]$

$60[30 ; 140]$

0.81

Automatic behaviors, \%

61.5

60.5

1.0

Treatment (complete information in 97 patients)

Untreated

16.7

10.8

0.61

Sodium oxybate, \%

5

16.2

0.14

Stimulants, \%

78.3

81

0.74

Data are median $\left[1^{\text {rst }}-3^{\text {rd }}\right.$ quartile]. No significant between-group differences. 
E. Chabani, et al.

Table 5 - Sleep mentation in patients with idiopathic hypersomnia, with

frequent/permanent night blackout vs. without night blackout

\begin{tabular}{lcccc}
\hline Idiopathic hypersomnia & $\begin{array}{c}\text { With } \\
\text { frequent/perman } \\
\text { ent night blackout }\end{array}$ & $\begin{array}{c}\text { Without night } \\
\text { blackout }\end{array}$ & P value & $\begin{array}{c}\text { P value } \\
\text { corrected }\end{array}$ \\
\hline
\end{tabular}

Number of patients

65

43

Dreaming characteristics

Dream recall frequency,

$2[1 ; 3.5]$

$5[2.5 ; 7.5]$

$<0.001^{*}$

$<0.001^{*}$

n/week

Dream recall frequency,

$1[0.5 ; 1.3]$

$1.5[1 ; 2]$

$<0.001^{*}$

$<0.001^{*}$

n/day

Brief images, n/week

$0.9[0 ; 1.5]$

$0[0 ; 1.05]$

0.161

0.241

Long scenarios, n/week

$1.5[0.9 ; 3.5]$

$1.5[0.9 ; 3.5]$

0.196

0.251

Mundane dreams, n/week

$0.9[0.9 ; 3.5]$

$1.5[0.9 ; 3]$

0.695

0.745

Vivid dreams, 1-6

$4[3 ; 5]$

$5[4 ; 6]$

$0.005^{*}$

0.010*

Bizarre dreams, n/week

$0.9[0.68 ; 1.5]$

$1.5[0.9 ; 2.5]$

0.016*

0.029*

Lucid dreams, n/month

$0.3[0.05 ; 3]$

$0.3[0.05 ; 3]$

0.068

0.113

Bad dreams, n/month

$1[0.12 ; 5]$

$1[0.12 ; 10]$

0.308

0.355

Nightmare, n/month

$0.25[0.12 ; 3]$

$0.25[0.12 ; 3]$

0.906

0.906

Feeling that sleep is deep,

$6[3.5 ; 6]$

$1.5[0.9 ; 6]$

$<0.001^{*}$

$0.001^{*}$ 
E. Chabani, et al.

$\begin{array}{lcccc}\begin{array}{l}\text { Total loss of } \\ \text { consciousness, n/week }\end{array} & 3.5[1.5 ; 6] & 0.9[0 ; 0.9] & <0.001^{*} & <0.001^{*} \\ \begin{array}{l}\text { Blank mind, n/week } \\ \text { Sleep mentation extends } \\ \text { what can be recalled, } \\ \text { n/week }\end{array} & 0.9[0 ; 3.5] & 1.5[0.9 ; 3.5] & 0.201 & 0.251 \\ \end{array}$

Data are median $\left[1^{\text {rst }}-3^{\text {rd }}\right.$ quartile]. * Significant $P$ values $(<0.05)$ and $P$ values corrected with the Benjamini-Hochberg procedure. 
E. Chabani, et al.

Table 6 - Sleep measures in patients with idiopathic hypersomnia with frequent/permanent night blackout vs. without night blackout

\begin{tabular}{|c|c|c|c|}
\hline Idiopathic hypersomnia & $\begin{array}{l}\text { With frequent or } \\
\text { permanent night } \\
\text { blackout }\end{array}$ & $\begin{array}{l}\text { Without night } \\
\text { blackout }\end{array}$ & $P$ value \\
\hline Number of patients & 51 & 39 & \\
\hline \multicolumn{4}{|l|}{ Habituation night } \\
\hline Sleep onset latency, min & $15.5[10 ; 27]$ & $13.5[9 ; 32]$ & 0.67 \\
\hline REM sleep latency, min & $98.5[71.5 ; 140]$ & $87.25[62.12 ; 116.5]$ & 0.22 \\
\hline WASO, min & $33[18.5 ; 61.5]$ & $28.5[18 ; 49.5]$ & 0.50 \\
\hline Sleep efficiency, \% & $91.1[83.2 ; 94.6]$ & $90.4[84.8 ; 95]$ & 0.62 \\
\hline $\begin{array}{l}\text { Total sleep time, Night } 1^{\#} \text {, } \\
\min \end{array}$ & $425[373 ; 466.5]$ & $428[401 ; 475]$ & 0.77 \\
\hline \multicolumn{4}{|l|}{ Sleep fragmentation, events $/ \mathrm{h}$} \\
\hline Arousal index & $21[15 ; 29.5]$ & $22[15 ; 42]$ & 0.50 \\
\hline Periodic leg movement index & $1.1[0 ; 4.4]$ & $1.1[0 ; 4.2]$ & 0.95 \\
\hline Apnea/hypopnea index & $0.7[0 ; 1.3]$ & $0.4[0.1 ; 1.8]$ & 0.98 \\
\hline \multicolumn{4}{|l|}{ Multiple sleep latency test } \\
\hline Mean latency, $\min$ & $12.2[7.6 ; 15.5]$ & $11.8[8.8 ; 14.2]$ & 0.84 \\
\hline SOREMP, $\mathrm{n}$ & $0[0 ; 1]$ & $0[0 ; 1]$ & 0.70 \\
\hline
\end{tabular}


E. Chabani, et al.

Total sleep time, Night 2 , $\min \quad 425[373 ; 466.5] \quad 428[401 ; 475] \quad 0.78$

Sleep stage, $\%$ of total sleep time

\begin{tabular}{|c|c|c|c|}
\hline N1 sleep & $2.5[1.4 ; 4.6]$ & $2.3[1.6 ; 3.5]$ & 0.56 \\
\hline N2 sleep & $48.1[41.8 ; 51.8]$ & $50.15[45.5 ; 55.2]$ & 0.18 \\
\hline N3 sleep & $24.5[19.8 ; 29.8]$ & $20.3[16 ; 25.7]$ & $0.030 *$ \\
\hline REM sleep & $25.3[21.8 ; 27.95]$ & $24.45[20.45 ; 28.8]$ & 0.65 \\
\hline Total sleep time/18h, $\min$ & $690.5[638 ; 729]$ & $679[651 ; 717.88]$ & 0.91 \\
\hline \multicolumn{4}{|c|}{$\begin{array}{l}\text { SOREM: sleep onset in REM period; WASO, duration of wakefulness after sleep onset. } \\
{ }^{4} \text { Night } 1 \text { was a habituation night, interrupted at 06:30 to perform the MLST. Night } 2 \text { was }\end{array}$} \\
\hline
\end{tabular}

